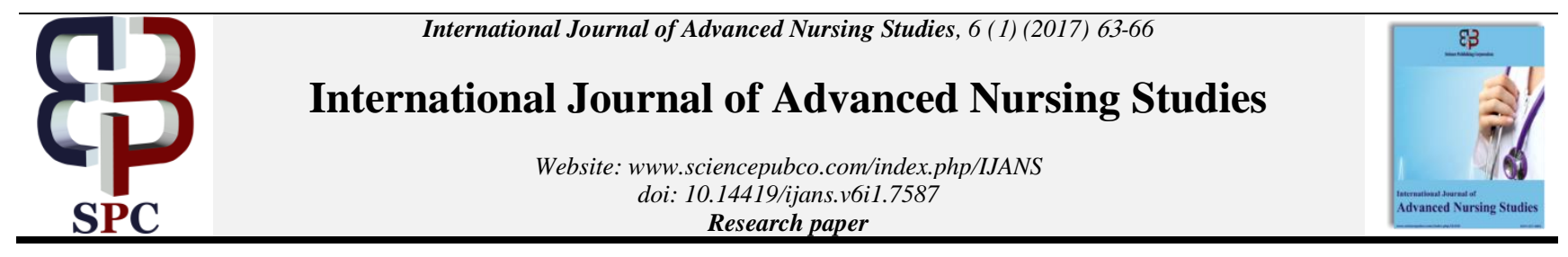

\title{
Relationship between health-related quality of life and self-esteem of adult patients receiving chemotherapy for cancer treatment
}

\author{
Sahar A. Abd-El mohsen *, Shaymaa Sayed Khalil \\ Adult Nursing Dept., Faculty of Nursing, Assiut University, Egypt \\ *Corresponding author E-mail: sara.saleh17@yahoo.com
}

\begin{abstract}
Purpose: To identify the relation between self-esteem and health related quality of life of adult cancer patients receiving chemotherapy and to identify the demographic variables that may have impact on health related quality of life of cancer patients receiving chemotherapy.

Methods: A cross-sectional, descriptive, correlational survey was utilized in this study. The study was conducted at the in-patient and out-patient clinic of oncology at South Egypt cancer institute. The sample consisted of 100 patients with the following inclusion criteria; adult patients diagnosed of any type of cancer, fully conscious and are willing to participate in the study. Two tools were used; 36-Item Short Form Health Survey Instrument and Rosenberg self-esteem questionnaire.

Results: The majority of the studied sample $(67 \%)$ was female, their age ranges from 40 years and above, they were not working and were having a breast cancer (38\%), there was a highly statistical significant difference in total HRQoL score and breast and lung cancer diagnosis.

Conclusion: A quarter of the studied sample was having a satisfactory quality of life while near the entire studied sample were having a good self-esteem. Age, sex and occupation were socio-demographic variables that have impact on patient's quality of life.
\end{abstract}

Keywords: Cancer Treatment; Chemotherapy; Health-Related Quality of Life; Self-Esteem.

\section{Introduction}

Cancer is a serious public health problem not only in Egypt but also worldwide, worsening in recent years because of population aging in developing countries such as Egypt. Cancer is different from other chronic diseases since its pathology can lead to deformities, pain and mutilation, also causing great psychological impact and negative feelings from the time of diagnosis (Nakashima et al., 2012).

Egypt was completely lacking incidence rates at national level until the results given in the National Cancer Registry Program (NCRP) were obtained (Abou-Zeid et al., 2006 and El-Attar, 2004). The commonest sites of cancer in males are liver (18.7\%), bladder $(12.7 \%)$, non-Hodgkin's lymphoma $(11.0 \%)$ and trachea, bronchus, and lung $(8.2 \%)$. The 4 sites represent $50.6 \%$ of all cancer in males. The commonest sites in females are breast (38.8\%), non-Hodgkin's lymphoma (8.5\%), liver (4.6\%), and ovary (4.5\%); all together represent $56.4 \%$ of cancer in females. The National Cancer Registry Program (NCRP) was established in 2008 and became the only source for cancer incidence in the country [National Cancer Registry Program of Egypt].

Quality of Life (QOL) assessment has been used in research and clinical practice to characterize the burden caused by cancer or its treatment, to select treatment options, to demonstrate the effect of rehabilitative efforts and to make policy decisions. It is agreed that health related quality of life (HRQOL) is a multidimensional construct that represents patient's perception of the effects of an illness and its therapy on his or her day-to-day functioning. A broad range of quality of life (QOL) domains can be assessed, but the physical, psychological, and social dimensions are the most important (Albert et al., 2002).

Self-esteem and quality of life are two major and important domains in management of cancer patients that must not be over looked and from the researcher's views, in Egyptian oncology units those two domains are totally neglected which reflects negatively on patient's outcome.

\section{Aims of the study}

1) Identify the relation between self-esteem and health related quality of life of adult cancer patients receiving chemotherapy.

2) Identify the demographic variables that may have impact on health related quality of life of cancer patients receiving chemotherapy.

\section{Research questions}

1) What is the experienced health related quality of life and self-esteem experienced by adult cancer patients receiving chemotherapy?

2) Is there a relation between self-esteem and health related quality of life of adult cancer patients receiving chemotherapy? 
3) Is there a relation between the demographic variables and health related quality of life of adult cancer patients receiving chemotherapy?

\section{Patients and methods}

\subsection{Research design}

A cross-sectional, descriptive, correlational survey was utilized in this study

\subsection{Setting}

In-patient and out-patient clinic of oncology at South Egypt cancer institute

\subsection{Sample}

A sample of 100 patients admitted to the oncology unit and outpatient oncology clinic with the following inclusion criteria; adult patients (age 18-65 years) diagnosed of any type of cancer, fully conscious and are willing to participate in the study.

\subsection{Tools: two tools were utilized in this study}

\subsubsection{Tool I: 36-item short form health survey instrument}

Will be used to assess patients health related quality of life, it also included demographic data of the included patients as age, sex marital status, and patient diagnosis.

\subsubsection{Tool II: Rosenberg self-esteem questionnaire}

\section{Methods}

\subsection{Administrative approval}

Official approval and administration permission was obtained from the head of South Egypt cancer institute after explaining the purpose and nature of the study.

\subsection{Ethical considerations}

The study will be approved by the Faculty ethics committee; an oral approval was obtained from the enrolled patients to participate in the study after explaining the nature and purpose of the study. The researchers explained that participation is voluntary and their participation status will not affect the care they will receive.

\subsection{Pilot study}

The study tool will be pre-tested on $10 \%$ of the patients who will be included in the study to examine clarity and feasibility of the used tools.

\section{Analysis of the results}

Table 1: Demographic Characteristics of the Studied Patients $N=100$

\begin{tabular}{|c|c|c|}
\hline Variables & Number & $\%$ \\
\hline \multicolumn{3}{|l|}{ Age group } \\
\hline $18<40$ ys & 33 & 33 \\
\hline 40- and above & 67 & 67 \\
\hline Male & 33 & 33 \\
\hline Female & 67 & 67 \\
\hline \multicolumn{3}{|l|}{ Occupation } \\
\hline Working & 30 & 30 \\
\hline Not working & 70 & 70 \\
\hline \multicolumn{3}{|l|}{ Diagnosis } \\
\hline Breast cancer & 38 & 38 \\
\hline lung & 16 & 16 \\
\hline Blood disease & 17 & 17 \\
\hline GIT & 29 & 29 \\
\hline
\end{tabular}

The majority of the studied sample $(67 \%)$ was female, their age ranges from 40 years and above, they were not working with a percent of 70 and were having a breast cancer $(38 \%)$.

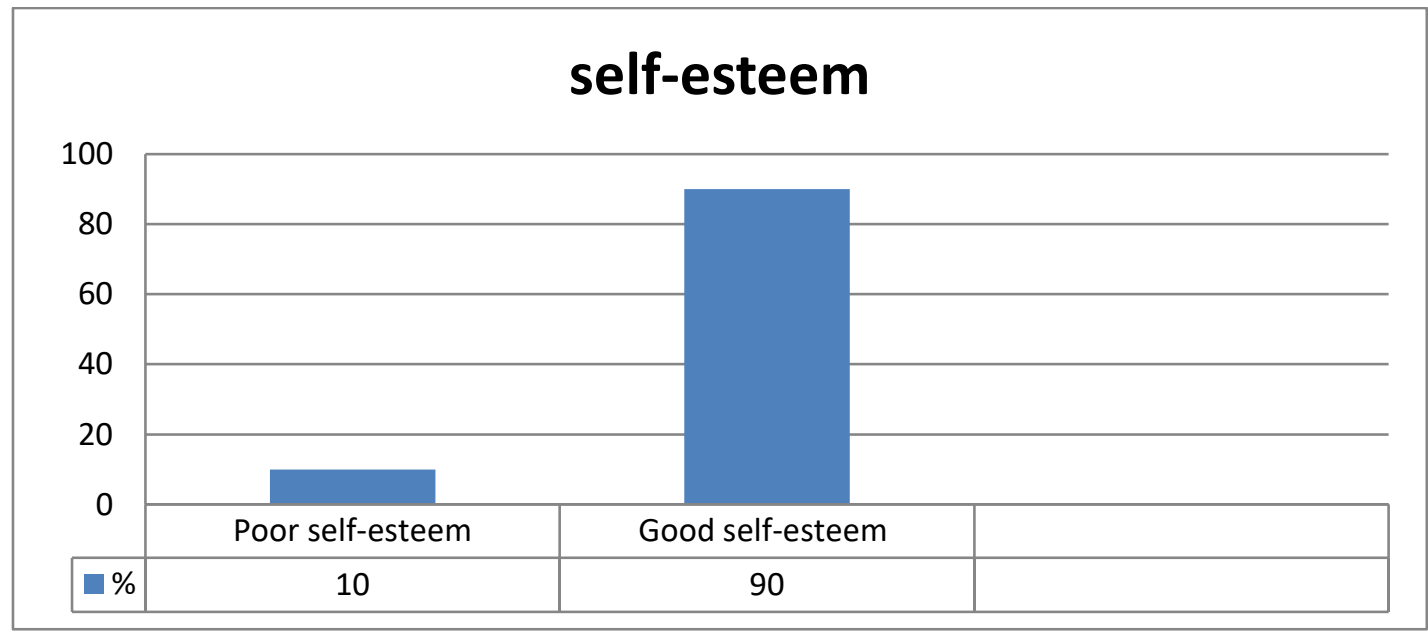

Fig. 1: Self-Esteem of the Studied Patients.

This figure shows that $90 \%$ of the studied patients were having good self-esteem 
Table 2: Mean Scores of Each Domain of Health Related Quality of Life

\begin{tabular}{lll}
\hline & $\mathrm{N}$ & Mean \pm Std. Deviation \\
\hline Physical function & 100 & $23.6600 \pm 6.31692$ \\
Role limitation due to physical health & 100 & $5.6500 \pm 1.83333$ \\
Role limitation due to emotional problems & 100 & $4.3000 \pm 1.43196$ \\
Energy & 100 & $18.8500 \pm 1.86610$ \\
Emotional well-being & 100 & $25.5900 \pm 2.07484$ \\
Social & 100 & $6.2900 \pm .96708$ \\
Pain & 100 & $6.1400 \pm 1.18082$ \\
General & 100 & $15.2400 \pm 1.31901$ \\
\hline
\end{tabular}

Looking at the domains of the health related quality of life it can be seen that; patients were having the higher score in their emotional well-being $(25.5900 \pm 2.07484)$ followed by the functional level $(23.6600 \pm 6.31692)$, and were having the lowest score in the role limitation due to emotional problems $(4.3000 \pm 1.43196)$.

Table 3: Correlation between Socio Demographic Data of Patients with Total and Subtotal Scores of SF-36

\begin{tabular}{|c|c|c|c|c|c|c|c|c|c|}
\hline \multirow{2}{*}{$\begin{array}{l}\text { Total and subtotal scores } \\
\text { of SF-36 }\end{array}$} & \multicolumn{3}{|l|}{$\begin{array}{l}\text { Age group } \\
\text { Mean } \pm \text { SD }\end{array}$} & \multicolumn{3}{|l|}{$\begin{array}{l}\text { Sex } \\
\text { Mean } \pm \text { SD }\end{array}$} & \multicolumn{2}{|l|}{$\begin{array}{l}\text { Occupation } \\
\text { Mean } \pm \text { SD }\end{array}$} & \multirow{2}{*}{$\begin{array}{l}\mathrm{P} . \\
\text { value }\end{array}$} \\
\hline & $\begin{array}{l}18-40 y s \\
N=33\end{array}$ & $\begin{array}{l}40 \text { and } \\
\text { above } \\
\mathrm{N}=67\end{array}$ & P. value & Male $=33$ & Female $=67$ & P. value & Working $=30$ & $\begin{array}{l}\text { Not work- } \\
\text { ing }=70\end{array}$ & \\
\hline Physical functioning & $26.8 \pm 5.3$ & $22.1 \pm 6.2$ & $.000 * *$ & $21.4 \pm 7.0$ & $24.7 \pm 5.6$ & $.01 * *$ & $21.7 \pm 7.3$ & $24.5 \pm 7.3$ & $.04 *$ \\
\hline $\begin{array}{l}\text { Role imitations due to } \\
\text { physical health }\end{array}$ & $6.3 \pm 1.7$ & $5.3 \pm 1.8$ & $0.012 * *$ & $5.15 \pm 1.6$ & $5.89 \pm 1.8$ & $.05^{*}$ & $5.3 \pm 1.7$ & $5.7 \pm 1.7$ & $.26 \mathrm{~ns}$ \\
\hline $\begin{array}{l}\text { Role limitations due to } \\
\text { emotional problems }\end{array}$ & $4.9 \pm 1.3$ & $3.9 \pm 1.4$ & $0.001 * *$ & $4.0 \pm 1.3$ & $4.44 \pm 1.4$ & $.142 \mathrm{~ns}$ & $4.0 \pm 1.3$ & $4.4 \pm 1.4$ & $.28 \mathrm{~ns}$ \\
\hline Energylfatigue & $18.6 \pm 1.6$ & $18.9 \pm 1.9$ & $0.49 \mathrm{~ns}$ & $18.6 \pm 1.8$ & $18.9 \pm 1.8$ & $.493 n s$ & $18.3 \pm 2.3$ & $19.05 \pm 1.60$ & $.09 \mathrm{~ns}$ \\
\hline Emotional well- being & $24.9 \pm 2.2$ & $25.9 \pm 1.9$ & $0.02 * *$ & $25.7 \pm 2.0$ & $25.5 \pm 2.0$ & $.573 \mathrm{~ns}$ & $25.4 \pm 2.6$ & $25.6 \pm 1.8$ & $.62 \mathrm{~ns}$ \\
\hline Social functioning & $6.0 \pm 0.8$ & $6.4 \pm 0.9$ & $0.09 \mathrm{~ns}$ & $6.3 \pm 1.1$ & $6.2 \pm 0.8$ & $.755 \mathrm{~ns}$ & $6.3 \pm 1.2$ & $6.2 \pm 0.8$ & $.60 \mathrm{~ns}$ \\
\hline Pain & $5.7 \pm 1.0$ & $6.3 \pm 1.1$ & $0.03 * *$ & $6.3 \pm 1.3$ & $6.0 \pm 1.0$ & $.132 \mathrm{~ns}$ & $6.5 \pm 1.2$ & $5.9 \pm 1.12$ & $.04 *$ \\
\hline General health & $15.0 \pm 1.4$ & $15.3 \pm 1.2$ & $0.2 \mathrm{Ns}$ & $15.7 \pm 0.9$ & $14.9 \pm 1.3$ & $.005^{* *}$ & $15.5 \pm 1.4$ & $15.1 \pm 1.2$ & $.19 \mathrm{~ns}$ \\
\hline Total score & $108.5 \pm 8.6$ & $104.3 \pm 8.7$ & $0.02 * *$ & $103.5 \pm 9.6$ & $106.8 \pm 8.3$ & $.082 \mathrm{~ns}$ & 103. $2 \pm 10.5$ & $106.7 \pm 7.9$ & $.07 \mathrm{~ns}$ \\
\hline
\end{tabular}

This table shows that regarding relation between HRQoL domains and age there was a significant relation in all domains except for energylfatigue, social functioning and general health, while for HRQoL and sex there was a significant relation with physical functioning (p. value $.01^{* *}$ ), Role imitations due to physical health (p. value $.05^{*}$ ) and General health (p. value $.005^{* *}$ ). And regarding relation to occupation a significant difference was found in Physical functioning (p. value .04*) and pain (p. value .04*).

Table 4: Correlation between Diagnosis of Patients with Total and Subtotal Scores of SF-36

\begin{tabular}{|c|c|c|c|c|c|c|c|c|}
\hline \multicolumn{9}{|c|}{ Diagnosis Mean \pm SD } \\
\hline \multirow{2}{*}{$\begin{array}{l}\text { Physical func- } \\
\text { tioning }\end{array}$} & \multirow{2}{*}{$\begin{array}{l}\text { breast cancer } \\
26.18 \pm 4.7\end{array}$} & \multirow{2}{*}{$\begin{array}{l}\mathrm{P} \text { value } \\
.000\end{array}$} & \multirow{2}{*}{$\begin{array}{l}\text { Lung } \\
17.68 \pm 6.19\end{array}$} & \multirow{2}{*}{$\begin{array}{l}\mathrm{P} \text { value } \\
.000\end{array}$} & \multirow{2}{*}{$\begin{array}{l}\text { Blood cancer } \\
24.58 \pm 5.74\end{array}$} & \multirow{2}{*}{$\begin{array}{l}\text { P value } \\
.437\end{array}$} & \multicolumn{2}{|c|}{$\begin{array}{l}\text { Gastrointestinal } \mathrm{P} \text { value } \\
\text { cancer }\end{array}$} \\
\hline & & & & & & & $23.10 \pm 6.44$ & .424 \\
\hline $\begin{array}{l}\text { Role imitations } \\
\text { due to physical } \\
\text { health }\end{array}$ & $6.42 \pm 1.88$ & .000 & $4.37 \pm 1.02$ & .000 & $5.70 \pm 1.72$ & .462 & $5.31 \pm 1.75$ & .461 \\
\hline $\begin{array}{l}\text { Role limitations } \\
\text { due to emotion- } \\
\text { al problems }\end{array}$ & $4.84 \pm 1.46$ & .000 & $3.25 \pm .77$ & .000 & $4.41 \pm 1.46$ & .471 & $4.10 \pm 1.34$ & .482 \\
\hline Energylfatigue & $19.44 \pm 1.36$ & .022 & $18.25 \pm 2.32$ & .069 & $19.05 \pm 1.02$ & .192 & $18.27 \pm 2.29$ & .121 \\
\hline $\begin{array}{l}\text { Emotional well- } \\
\text { being }\end{array}$ & $25.84 \pm 1.60$ & .339 & $25.18 \pm 3.41$ & .472 & $25.35 \pm 2.17$ & .638 & $25.62 \pm 1.63$ & .664 \\
\hline $\begin{array}{l}\text { Social function- } \\
\text { ing }\end{array}$ & $6.15 \pm .82$ & .774 & $6.06 \pm 1.61$ & .825 & $6.52 \pm .79$ & .728 & $6.44 \pm .73$ & .735 \\
\hline Pain & $5.78 \pm 1.06$ & .001 & $6.87 \pm 1.02$ & .001 & $5.88 \pm .99$ & .217 & $6.34 \pm 1.31$ & .185 \\
\hline General health & $14.71 \pm 1.31$ & .019 & $15.68 \pm 1.44$ & .028 & $15.35 \pm 1.32$ & .452 & $15.62 \pm 1.04$ & .481 \\
\hline Total score & $109.39 \pm 7.31$ & .000 & $97.37 \pm 10.41$ & .000 & $106.88 \pm 7.45$ & .381 & $106.88 \pm 7.68$ & .379 \\
\hline
\end{tabular}

This table illustrates the relation between health related quality of life domains and patient diagnosis; it shows that there was a highly statistical significant difference in total HRQoL score and breast cancer diagnosis and lung cancer diagnosis.

Table 5: Relation between Self-Esteem and Health Related Quality of Life

\begin{tabular}{llll} 
& HRQoL & Unsatisfactory & \\
& Satisfactory & 9 & \\
\hline Poor self-esteem & 1 & 65 & 10 \\
Good self-esteem & 25 & 74 & 90 \\
Total & 26 & 100 \\
\hline
\end{tabular}

This table shows the relation between health-related quality of life and self-esteem of adult cancer patients receiving chemotherapy; there was no statistically significant difference between both variables.

\section{Discussion}

Several studies have indicated that the assessment of quality of life does not only shed light on the life experiences of people with acute illnesses, but that it could be of great value in planning interventions that may improve people's quality of life. Determining 
also which factors influence quality of life (which consequently affects all dimensions of an individual's life), are well documented in numerous scientific studies and hence this study was an attempt to determine these factors.

The ultimate goal of quality of life research must be to improve medical care and inform medical decision making. Individual patients who incorporate quality of life considerations into their decisions generally feel better about their treatment choices, are more satisfied overall with their care, and are less likely to experience regret. The evaluation of quality of life, as perceived by the patient, allows for the assessment of subjective morbidity that, although not always life-threatening, may cause considerable distress. Such minor morbidity is often overlooked during the busy routines of clinical care (Cassileth et al., 1989).

The present study revealed that the majority of the studied sample was female and having breast cancer and this comes in accordance with the national prevalence of breast cancer among female as it was the commonest type of cancer among females in Egypt. It also showed that the majority of the sample was not working and this comes in accordance with the sex of the majority of the sample who were female as the nature of the Egyptian community most of studied sample were house wives. And regarding their age which showed that it was 40 and older the 2008-2011 cancer incidence report revealed that breast cancer incidence increases with age (Amal et al., 2014)

The majority of the studied sample were having good self-esteem and the highest percent on the quality of life domains was in the emotional state and this could be related to the strong Egyptian (especially in Upper Egypt) bonds, followed by the physical activity level which also could be related to their nature as house wives so they will be much more energetic.

Regarding relation between quality of life and Sociodemographic variables there was a highly statistically significant difference between age and HRQoL; patients younger than 40 years of age were having a better quality of life and as there sex it was revealed that females were having a better scores in physical functioning and the levels of pain as females more energetics and they have a higher threshold of pain.

Finally there was no relation between self-esteem and health related quality of life as shown from the present study results which revealed that the majority of those who have a good self -esteem were having unsatisfactory quality of life and vice-versa.

\section{Conclusion and recommendations}

From the present study results it can be concluded that; a quarter of the studied sample was having a satisfactory quality of life while near all of the studied sample were having a good selfesteem.

Age, sex and occupation were socio-demographic variables that have impact on patient's quality of life.

There is no relationship between self-esteem and health related quality of life of adult cancer patients receiving chemotherapy.

Based on the results of the present study the following recommendations are drawn; An internationally accepted version of a health related quality of life tool to be available in the oncology unit and nurses well acquainted with using it to allow them to assess patient's quality of life regularly, a social worker and religious specialist are to be part of the oncology treatment team for managing quality of life issues from their perspective.

\section{References}

[1] Albert US, Koller M, Lorenz W, (2002): Quality of life profile: from measurement to clinical application. The Breast; 11:324-34. https://doi.org/10.1054/brst.2002.0419.

[2] Amal S. Ibrahim, Hussein M. Khaled, Nabiel NH Mikhail, Hoda Baraka, and Hossam Kamel, (2014): Cancer Incidence in Egypt: Results of the National Population-Based Cancer Registry Program, journal of Cancer Epidemiology, Volume 2014.
[3] Cassileth BR, Soloway MS, Vogelzang NJ, (1989): Patients' choice of treatment in stage D prostate cancer. Urology; 33(5 Suppl.): 57 62 https://doi.org/10.1016/0090-4295(89)90108-8.

[4] El-Attar, Cancer statistics, NCI, (2004): Department of Biostatics and Epidemiology, NCI, Cairo, Egypt, 2005, http://www.nci.cu.edu.eg/lectures/NCI2004.ppt.

[5] Nakashima JP, Koifman RJ, Koifman S. Incidência de câncer na Amazônia ocidental: estimativa de base populacional de Rio Branco, Acre, Brasil, (2012): 2007-2009. Cad Saúde Pública. 28(11):2125-2132. 311X2012001100012. https://doi.org/10.1590/S0102

6] National Cancer Registry Program of Egypt, http://www.cancerregistry.gov.eg.

[7] W. Abou-Zeid, F. El-Khwsky, S. Mokhtar, M. Sherif, and N. Mahdy, (2006): "Descriptive epidemiology and multivariate survival analysis of oral and pharyngeal malignancies in Alexandria," Journal of the Medical Research Institute, vol. 27, no. 4, pp. 262-270. 